\title{
Always randomize as late as possible
}

\author{
Erik van Werkhoven ${ }^{1}$ (D) Parvin Tajik ${ }^{2} \cdot$ Patrick M. Bossuyt $^{1}$
}

Received: 11 March 2019 / Accepted: 27 March 2019 / Published online: 8 April 2019

(c) The International Gastric Cancer Association and The Japanese Gastric Cancer Association 2019

\section{Dear Editor,}

We read the recent article by Claassen et al. [1], with the intriguing title "Impact of upfront randomization for postoperative treatment on quality of surgery in the CRITICS gastric cancer trial". In the CRITICS trial, participants received neo-adjuvant chemotherapy and surgery, followed by adjuvant therapy consisting of either chemotherapy (CT) or chemoradiotherapy (CRT) [2].

The problem that Claassen et al. discuss is the timing of the randomization in the CRITICS trial. Randomization was done "upfront", before the start of the neo-adjuvant chemotherapy, instead of after surgery. The reason given is that the US Intergroup 0116 trial [3], which randomized after surgery, was criticized on the grounds that pathology results were known at the time of randomization.

As acknowledged in the original report, this "upfront" randomization hampers any direct comparison of the postoperative therapies [2]. A direct comparison would have been possible if randomization was performed "as late as possible", at the time where a decision to go one way or the other has to be made [4].

Claassen et al. suggest that their analysis of one of the possible causes of bias in the CRITICS trial, the quality of surgery, demonstrates that this potential design weakness does not affect the interpretation of its results. They even write that "Post-operative randomization $[. .$.$] harbors the$ risk of selection bias, as only a proportion of patients will be able to start postoperative treatment".

This comment refers to the article available at https://doi. org/10.1007/s10120-018-0875-1.

Erik van Werkhoven

e.d.vanwerkhoven@amc.uva.nl

1 Department of Clinical Epidemiology, Biostatistics and Bioinformatics, Amsterdam UMC, University of Amsterdam, Amsterdam, The Netherlands

2 Department of Pathology, Amsterdam UMC, University of Amsterdam, Amsterdam, The Netherlands
We believe this statement is misleading.

Claassen et al. argue that with post-operative randomization, patients would have been excluded from randomization "due to disease progression, postoperative complications, poor condition, refusal, or even death". But the post-operative therapy can only be given to patients who are alive and able to undergo the therapy. From a regulatory perspective and from a decision-making point of view, participants should be similar to patients who would receive the intervention if it was part of usual care [5]. So, if pathology results are in practice available at the time of the choice between $\mathrm{CT}$ and CRT, then a design with randomization at that point would address the objective of the pragmatic trial more adequately.

Selection bias should be prevented by assessing eligibility criteria and seeking informed consent "upfront". Selective dropout may still occur; so an intention-to-treat analysis should be done, with additional sensitivity analyses if necessary. In the CRITICS trial, in which $39 \%$ of the patients randomly allocated to post-operative treatment never started it, any analysis of long-term outcome by treatment arm counting time from surgery is at risk of bias, from observed as well as from unobserved sources [6]. We, therefore, should like to encourage the CRITICS investigators to do further sensitivity analyses on their data, for example, using propensity score matching or inverse probability of treatment weighting. Such methods may reduce the bias, although only from observed factors.

We recognize that randomization "as late as possible", although it is always desirable, may be impossible in specific exceptional cases [7]. But any statements suggesting that it causes selection bias must be firmly dismissed.

\section{Compliance with ethical standards}

Conflict of interest Erik van Werkhoven declares that he has no conflict of interest. Parvin Tajik declares that she has no conflict of interest. Patrick M. Bossuyt declares that he has no conflict of interest. 
Ethical approval This article does not contain any studies with human participants or animals performed by any of the authors.

\section{References}

1. Claassen YHM, Hartgrink HH, De Steur WO, Dikken JL, van Sandick JW, Van Grieken NCT, et al. Impact of upfront randomization for postoperative treatment on quality of surgery in the CRITICS gastric cancer trial. Gastric Cancer. 2018;22(2):369-76.

2. Cats A, Jansen EPM, van Grieken NCT, Sikorska K, Lind P, Nordsmark M, et al. Chemotherapy versus chemoradiotherapy after surgery and preoperative chemotherapy for resectable gastric cancer (CRITICS): an international, open-label, randomised phase 3 trial. Lancet Oncol. 2018;19:616-28.

3. Macdonald JS, Smalley SR, Benedetti J, Hundahl SA, Estes NC, Stemmermann GN, et al. Chemoradiotherapy after surgery compared with surgery alone for adenocarcinoma of the stomach or gastroesophageal junction. N Engl J Med. 2001;345:725-30.

4. Peto R, Pike MC, Armitage P, Breslow NE, Cox DR, Howard SV, et al. Design and analysis of randomized clinical trials requiring prolonged observation of each patient. I. Introduction and design. Br J Cancer. 1976;34(6):585-612.

5. Ford I, Norrie J. Pragmatic trials. N Engl J Med. 2016;375(5):454-63.

6. Piantadosi S. Clinical trials: a methodologic perspective. 2nd ed. Hoboken: Wiley; 2005.

7. Durrleman S, Simon R. When to randomize? J Clin Oncol. 1991;9(1):116-22.

Publisher's Note Springer Nature remains neutral with regard to jurisdictional claims in published maps and institutional affiliations. 